\title{
Docetaxel/zoledronic acid combination triggers apoptosis synergistically through downregulating antiapoptotic Bcl-2 protein level in hormone-refractory prostate cancer cells
}

\author{
B. Karabulut ${ }^{\text {a }}$, C. Erten ${ }^{\text {a }}$, M.K. Gul ${ }^{\text {a }}$, E. Cengiz ${ }^{\text {a }}$, B. Karaca ${ }^{\text {a }}$, Y. Kucukzeybek ${ }^{\text {a }}$, \\ G. Gorumlu ${ }^{\text {a }}$, H. Atmaca ${ }^{\text {b }, ~ S . ~ U z u n o g l u ~}{ }^{\text {b }}$, U.A. Sanli ${ }^{\text {a }}$, Y. Baran ${ }^{\text {c }}$, R. Uslu ${ }^{\text {a } *}$ \\ ${ }^{a}$ Division of Medical Oncology, Tulay Aktas Oncology Hospital, School of Medicine, Ege University, Bornova, Izmir, Turkey \\ ${ }^{\mathrm{b}}$ Section of Molecular Biology, Department of Biology, Faculty of Science and Arts, Celal Bayar University, Muradiye, Manisa, Turkey \\ ${ }^{\mathrm{c}}$ Department of Molecular Biology and Genetics, Faculty of Science, Izmir Institute of Technology, Urla, Izmir, Turkey
}

Received 8 July 2008; revised 24 July 2008; accepted 29 November 2008

\begin{abstract}
Docetaxel, a semi-synthetic taxane analogue, is used effectively in the treatment of metastatic prostate cancer. Zoledronic acid, the most potent member of bisphosphonates, has shown pleiotropic anti-tumoral effects on prostate cancer cells. We have explored the possible additive/ synergistic effects and the apoptotic pathways induced by combination treatment of docetaxel and zoledronic acid in hormone and drug refractory, PC-3 and DU-145 prostate cancer cells. Combination of docetaxel and zoledronic acid synergistically inhibits cell growth in PC-3 and DU-145 cells. Moreover, this effect was due to downregulation of antiapoptotic protein Bcl-2 in PC-3 and DU-145 cells. In conclusion, docetaxel/zoledronic acid combination is potentially a novel and effective approach for the treatment of prostate cancer.

(C) 2008 International Federation for Cell Biology. Published by Elsevier Ltd. All rights reserved.
\end{abstract}

Keywords: Prostate cancer; PC-3; DU-145; Docetaxel; Zoledronic acid; Bcl-2

\section{Introduction}

Prostate cancer is a worldwide significant health problem because of its high incidence and mortality particularly in elderly men, while the androgen-independent state of the disease has the worst prognosis. There is no standard treatment modality for this condition. Therefore, it is vitally important to explore novel agents in order to treat androgen-independent forms of the disease effectively (Zhao et al., 2004).

In the 1980s, docetaxel, a semi-synthetic taxane analogue from the European yew (Taxus baccata) was identified. Approximately 10 years ago, after in vitro studies, docetaxel was introduced to be an effective treatment option for androgen-independent prostate cancer (Gligorov and Lotz,

\footnotetext{
* Corresponding author. Tel.: +90 23239039 06; fax: +90 2323747321 . E-mail address: ruchan.uslu@ege.edu.tr (R. Uslu).
}

2004; Hanauske et al., 1992). As the results of clinical studies of its effect on prostate cancer, docetaxel is currently approved as the most active agent used in the treatment of metastatic prostate cancer (Berthold et al., 2008). Docetaxel binds to tubulin subunits and inhibits the disassembly of microtubules that normally occurs during cell cycle progression. It can also induce apoptosis significantly through inactivating the antiapoptotic Bcl-2 protein by its phosphorilation (Haldar et al., 1997).

Zoledronic acid is the most potent member of bisphosphonate family used mainly for the treatment of skeletal metastases of different tumor types, including prostate cancer (Corey et al., 2003). Furthermore, there is strong evidence that zoledronic acid also has anti-tumoral activities on many types of human cancers via a variety of mechanisms, including growth factor release, cell adhesion, antiangiogenic effects and apoptosis. Several in vitro studies have indeed demonstrated 
varying antiproliferative and cytostatic effects of zoledronic acid on prostate cancer cells (Dumon et al., 2004; Lee et al., 2001; Oades et al., 2003).

Based on these data, we have explored the possible additive/synergistic cytotoxic and apoptotic effects of combination treatment of docetaxel and zoledronic acid in hormonerefractory PC-3 and DU-145 prostate cancer cells. We have also examined for the apoptotic pathways induced in these cells exposed to docetaxel or zoledronic acid and combination of both. In this study, we tried to provide a novel drug combination for the treatment of hormone-refractory prostate cancer.

\section{Materials and methods}

\subsection{Chemicals}

Cell culture supplies were obtained from Biological Industries (Kibbutz Beit Haemek, Israel). Zoledronic acid was a generous gift from Novartis Pharmaceuticals Inc. (Basel, Switzerland). Docetaxel was obtained from Sigma Chemical Co (USA). The stock solution of zoledronic acid was prepared at a concentration of $10 \mathrm{mM}$ in distilled water and aliquots were stored in $-20{ }^{\circ} \mathrm{C}$. Stock solution of docetaxel $(10 \mathrm{mM})$ was prepared in DMSO and the DMSO concentration in the assay did not exceed $0.1 \%$. All other chemicals, unless mentioned, were obtained from Sigma. Anti-Bcl-2 antibody was obtained from Millipore Upstate USA (Charlottesville, VA).

\subsection{Cell lines and culture conditions}

Human PC-3 and DU-145 prostate cancer cells were obtained from ICLC (Genova, Italy). The cells were grown in RPMI-1640 supplemented with $10 \%$ heat-inactivated fetal bovine serum (FBS), 1\% L-glutamine, 1\% penicillin-streptomycin. Both cells were grown in incubators at $37{ }^{\circ} \mathrm{C}$ in the presence of $5 \% \mathrm{CO}_{2}$.

\subsection{XTT cytotoxicity assay}

The cytotoxic effect of docetaxel or zoledronic acid and their combination on PC-3 and DU-145 cells were evaluated by XTT cell proliferation kit (Roche Applied Science, Mannheim, Germany). Cells $\left(10^{4}\right.$ cells/well) were plated in a 96well plate in $200 \mu \mathrm{l}$ culture medium in the absence or presence of increasing concentrations of agents after verifying cell viability by trypan blue exclusion test. After $72 \mathrm{~h}$ of incubation, $50 \mu \mathrm{l}$ of XTT labeling mixture was added to each well and incubated for $4 \mathrm{~h}$. The optical density was measured at $450 \mathrm{~nm}$ with a reference wavelength at $650 \mathrm{~nm}$ in a microplate reader (Beckman Coulter, DTX 880 Multimode Reader).

\subsection{DNA fragmentation analyses}

Apoptosis was evaluated by ELISA using Cell Death Detection ELISAPLUS kit (Roche Applied Science,
Mannheim, Germany) and was confirmed by measuring the enzyme activity of caspase $3 / 7$. The relative amounts of mono- and oligonucleosomes generated from the apoptotic cells were quantified using monoclonal antibodies directed against DNA and histones by ELISA. Briefly, cytoplasmic fraction of the untreated control and zoledronic acid or docetaxel and the combination of both treated cells were transferred onto a streptavidin-coated plate and incubated for $2 \mathrm{~h}$ at room temperature with a mixture of peroxidase conjugated anti-DNA and biotin labeled antihistone. The plate was washed thoroughly, incubated with 2,29-azino-di-[3-ethylbenzthiazolinesulfonate] diammonium salt (ABTS) and finally the absorbance was read at $405 \mathrm{~nm}$ with a reference wavelength at $490 \mathrm{~nm}$ (Beckman Coulter, DTX 880 Multimode Reader). All the experiments were performed in duplicate in enzyme-linked immunosorbent assay (ELISA) assays.

\subsection{Caspase 3/7 enzyme activity assay}

The Caspase-Glo 3/7 assay (Promega, Madison, WI) was used to measure caspase $3 / 7$ enzyme activity according to the manufacturer's instructions. PC-3 and DU-145 cells at $10^{4}$ cells/well were plated in a 96-well plate in $100 \mu \mathrm{l}$ culture medium in the absence or presence of increasing concentrations of docetaxel or zoledronic acid and the combination of both. $100 \mu \mathrm{l}$ of Caspase-Glo 3/7 reagent was added to each well and incubated at room temperature for $1 \mathrm{~h}$. Finally, the luminescence of each sample was measured at luminometer (Beckman Coulter, DTX 880 Multimode Reader).

\subsection{Western blot analysis}

PC-3 and DU-145 cells were grown for $72 \mathrm{~h}$ in the absence or presence of docetaxel or zoledronic acid, or a combination of both at $37^{\circ} \mathrm{C}$. To prepare cell lysates for Western immunoblot analysis, cell pellets were lysed in buffer containing $20 \mathrm{mM}$ Tris(tris(hydroxymethyl)aminomethane)- $\mathrm{HCl} \quad(\mathrm{pH}$ 8.0), $137 \mathrm{mM} \mathrm{NaCl}, 10 \%$ glycerol, $1 \%$ Triton X-100, $1 \mathrm{mM}$ $\mathrm{Na}_{3} \mathrm{VO}_{4}, 25 \mathrm{mM}$ glycerophosphate and phosphatase inhibitor cocktail 1 (Sigma, USA). After centrifugation at $14,000 \mathrm{~g}$ for $15 \mathrm{~min}$, protein concentrations were quantitated in duplicate by the Bradford method (Bio-Rad Laboratories, Hercules, CA). Equal amounts of protein were separated on an SDSpolyacrylamide gel electrophoresis (PAGE) and transferred to polyvinylidene difluoride Immobilon-P membranes (Bio-Rad Laboratories, Hercules, CA). The membranes were blocked with 5\% nonfat drymilk prepared in Tris-buffered saline containing $0.1 \%$ Tween 20 (TBST0.1) at room temperature for $1 \mathrm{~h}$ and then incubated with primary antibodies diluted either in 5\% BSA for Bcl-2 protein detection at room temperature for $1 \mathrm{~h}$. Dilutions of primary antibodies were prepared according to the manufacturer's instructions. Following several washes in TBST, membranes were incubated with appropriate secondary antibodies (1:2000 dilution, Millipore Upstate USA, Charlottesville, VA) at room temperature for $1 \mathrm{~h}$. The protein bands recognized by the antibodies were visualized by the Kodak Gel Logic 1500 Imaging System. 


\subsection{Statistical analysis}

The data were analyzed using GraphPad PRISM software (version 5) (San Diego, CA, USA). All experiments were set up in triplicate and the results were expressed as the mean \pm standard deviation (SD). The paired Student's $t$-test was used to compare the differences between paired samples. Differences were considered significant at $P$ value below 0.05 . Median dose effect analysis was used to assess the interaction between the agents. The combination index (CI) values (Chou and Talalay, 1984) were calculated by using Biosoft CalcuSyn program (Ferguson, MO, USA) and CI was used to express synergism $(\mathrm{CI}<1)$, additive effect $(\mathrm{CI}=1)$, or antagonism $(\mathrm{CI}>1)$.

\section{Results}

\subsection{Antiproliferative effects of docetaxel and zoledronic acid on PC-3 and DU-145 cells}

To examine antiproliferative effect of docetaxel and zoledronic acid for each agent, we incubated PC-3 and DU-145 cells in the absence or presence of increasing concentrations of
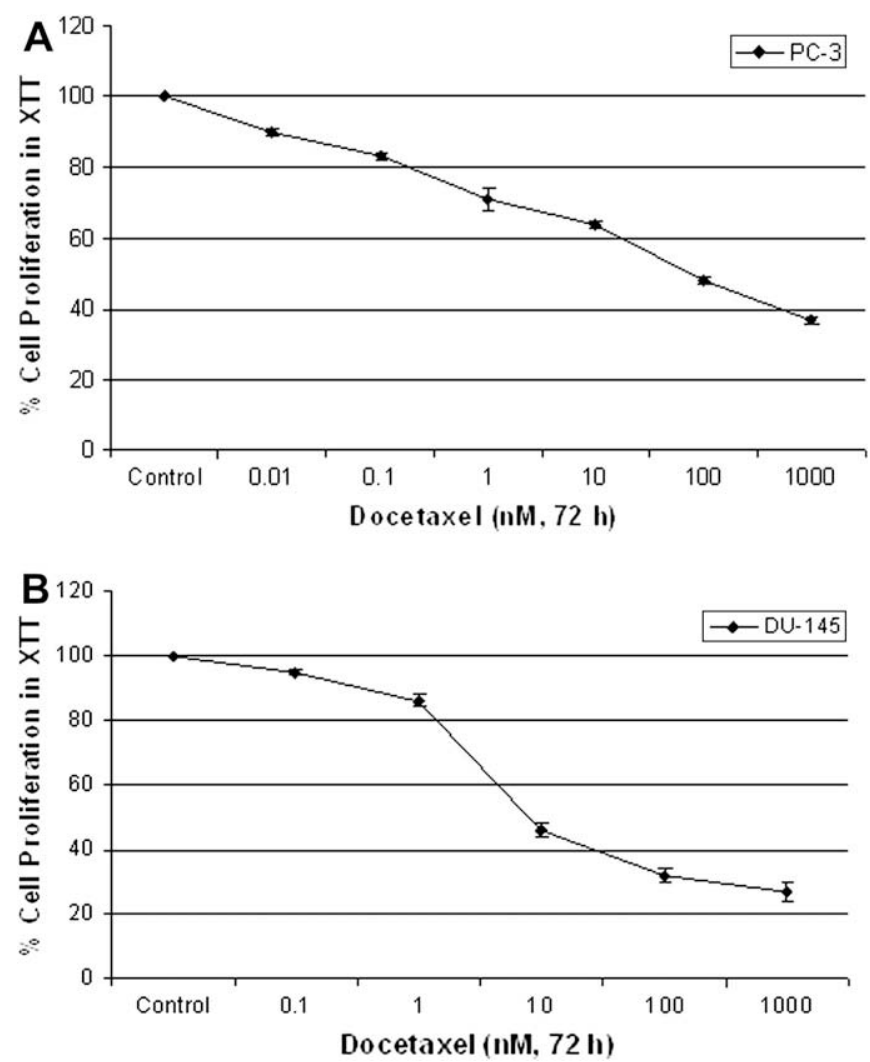

Fig. 1. A. Effects of docetaxel on the growth of PC-3 cells. B. Effects of docetaxel on the growth of DU-145 cells. The $\mathrm{IC}_{50}$ concentration of docetaxel was calculated from cell proliferation plots. The XTT assays were performed using triplicate samples in at least 2 independent experiments. The error bars represent the standard deviations and, when not seen, they are smaller than the thickness of the lines on the graphs. Statistical significance was determined using two-way analysis of variance and found to be significant $(P<0.05)$.
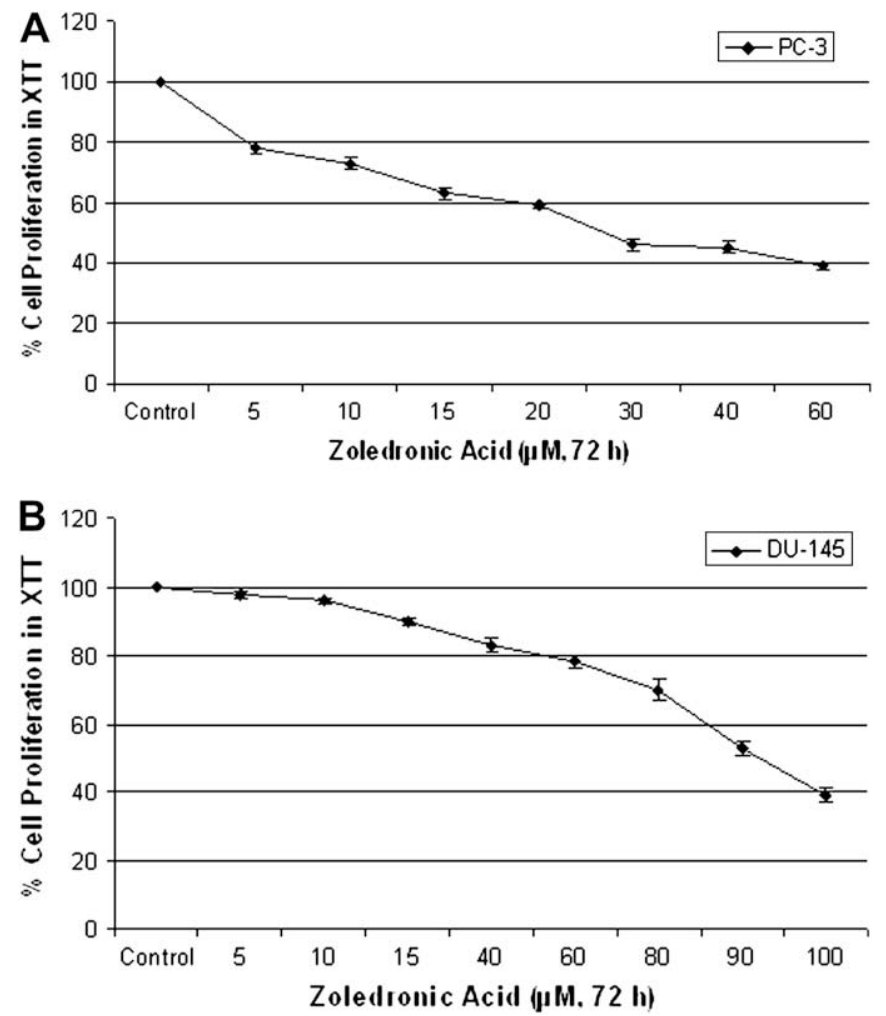

Fig. 2. A. Effects of zoledronic acid on the growth of PC-3 cells. B. Effects of zoledronic acid on the growth of DU-145 cells. The $\mathrm{IC}_{50}$ concentration of zoledronic acid was determined by XTT assay for each cell line as described. The XTT assays were performed using triplicate samples in at least 2 independent experiments. The error bars represent the standard deviations and, when not seen, they are smaller than the thickness of the lines on the graphs. Statistical significance was determined using two-way analysis of variance, and was significant $(P<0.05)$.

docetaxel and zoledronic acid for 24,48 and $72 \mathrm{~h}$ through XTT cell proliferation assay. PC-3 and DU-145 cells were exposed to docetaxel $(0.01-1000 \mathrm{nM})$ and zoledronic acid $(5-100 \mu \mathrm{M})$ for 24,48 and $72 \mathrm{~h}$ and $\mathrm{IC}_{50}$ values were calculated from cell proliferation plots. Cytotoxicity was increased in time and dose-dependent manner for each agent (data not shown). Highest cytotoxicity was observed at $72 \mathrm{~h}$ for each agent and $\mathrm{IC}_{50}$ values of docetaxel in PC-3 (Fig. 1A) and DU-145 (Fig. 1B) cells were 12 and $9 \mathrm{nM}$, respectively. In zoledronic acid treated PC-3 (Fig. 2A) and DU-145 cells (Fig. 2B), $\mathrm{IC}_{50}$ values were calculated to be 27 and $92 \mu \mathrm{M}$, respectively, indicating that $\mathrm{PC}-3$ cells were more sensitive to

Table 1

Combination index values of docetaxel or zoledronic acid alone and the combination of both on growth inhibition of PC-3 cells. Combination index (CI) values were calculated from the XTT cell proliferation assays. The data represent the mean $\pm \mathrm{SD}$ of 3 independent experiments.

\begin{tabular}{lll}
\hline Drugs & CI & Description \\
\hline Docetaxel $(0.01 \mathrm{nM})+$ ZA $(5 \mu \mathrm{M})$ & 0.102 & Strong synergism \\
Docetaxel $(0.01 \mathrm{nM})+$ ZA $(10 \mu \mathrm{M})$ & 0.129 & Strong synergism \\
Docetaxel $(0.01 \mathrm{nM})+$ ZA $(15 \mu \mathrm{M})$ & 0.300 & Synergism \\
Docetaxel $(100 \mathrm{nM})+$ ZA $(30 \mu \mathrm{M})$ & 0.229 & Synergism \\
\hline
\end{tabular}


Table 2

Combination index values of docetaxel or zoledronic acid alone and the combination of both on growth inhibition of DU-145 cells. Combination index (CI) values were calculated from the XTT cell proliferation assays. The data represent the mean $+\mathrm{SD}$ of 3 independent experiments.

\begin{tabular}{lll}
\hline Drugs & CI & Description \\
\hline Docetaxel $(0.1 \mathrm{nM})+$ ZA $(5 \mu \mathrm{M})$ & 0.026 & Strong synergism \\
Docetaxel $(0.1 \mathrm{nM})+$ ZA $(15 \mu \mathrm{M})$ & 0.088 & Strong synergism \\
Docetaxel $(1 \mathrm{nM})+$ ZA $(10 \mu \mathrm{M})$ & 0.025 & Strong synergism \\
\hline
\end{tabular}

zoledronic acid as compared to DU-145 cells as a bit more resistant to docetaxel.

\subsection{Combination of docetaxel and zoledronic acid suppressed cell growth significantly more than any agent alone did, in human prostate cancer cells}

To examine the cell growth suppressor effects of docetaxel and zoledronic acid combination, PC-3 and DU-145 cells were treated with increasing concentrations of both drugs at the same time for 24,48 and $72 \mathrm{~h}$. The synergism or additivity was calculated via combination index (CI) by using Biosoft Calcusyn Program. $\mathrm{CI}=1$ indicates additive effect, $\mathrm{CI}>1$ indicates antagonism, $\mathrm{CI}<1$ indicates synergism and $\mathrm{CI}<0.5$ shows strong synergy (Chou and Talalay, 1984). Combination of various concentrations of docetaxel and zoledronic acid at different time points were evaluated. Results showed that at $72 \mathrm{~h}$, significant growth suppression on human prostate cancer cells as compared to any agent alone as shown in Tables 1 and 2 .

The XTT cell proliferation data indicated that $0.01 \mathrm{nM}$ docetaxel and $5 \mu \mathrm{M}$ zoledronic acid resulted in 8 and $10 \%$ decrease in proliferation of PC-3 cells, respectively, while the combination of both at the same concentrations resulted in $65 \%$ decrease in cell proliferation, as compared to untreated controls (Fig. 3). On the other hand, $0.1 \mathrm{nM}$ docetaxel or $5 \mu \mathrm{M}$ zoledronic acid resulted in 5 and $2 \%$ decrease in proliferation of DU-145 cells, respectively, as the combination of both at the same doses caused $70 \%$ decrease in cell proliferation as compared to untreated controls (Fig. 4).

For PC-3 cells exposed to $0.01 \mathrm{nM}$ docetaxel and 5 or $10 \mu \mathrm{M}$ zoledronic acid, the CI values were calculated to be 0.102 or 0.129 , respectively, indicating that the combinations of docetaxel and zoledronic acid at these concentrations showed a very strong synergism. Combination index analyses conducted for DU-145 cells showed that combination treatment of $0.1 \mathrm{nM}$ plus $5 \mu \mathrm{M}$ zoledronic acid, $0.1 \mathrm{nM}$ docetaxel plus $15 \mu \mathrm{M}$ zoledronic acid, and $1 \mathrm{nM}$ docetaxel plus $10 \mu \mathrm{M}$ zoledronic acid resulted in strong synergisms.

\subsection{Effects of the sequential treatment}

The previous findings demonstrated that tumor cells with docetaxel and zoledronic acid resulted in significant synergy at $72 \mathrm{~h}$. We examined the effect of sequential treatment of PC-3 and DU-145 cells with either docetaxel or zoledronic acid and subsequent treatment with the second agent. Pretreatment of tumor cells with docetaxel for $36 \mathrm{~h}$ and wash and then treatment for an additional $36 \mathrm{~h}$ with zoledronic acid resulted in synergistic cytotoxicity in both PC-3 and DU-145 cells. Also, pretreatment of tumor cells with zoledronic acid for $36 \mathrm{~h}$ and wash and then treatment for an additional $36 \mathrm{~h}$ with docetaxel resulted in synergistic cytotoxicity in both PC-3 and DU-145 cells. So we could not show any effect of sequential treatment on synergy obtained with docetaxel and zoledronic acid (data not shown).

\subsection{A significant increase in DNA fragmentation was detected in response to combination of docetaxel and zoledronic acid compared to any agent alone in PC-3 and DU-145 cells}

To examine the induction of apoptosis in response to docetaxel or zoledronic acid and the combination of both in prostate cancer cells, we incubated the cells in the presence of the anticancer agents alone or a combination of both for $72 \mathrm{~h}$ and then

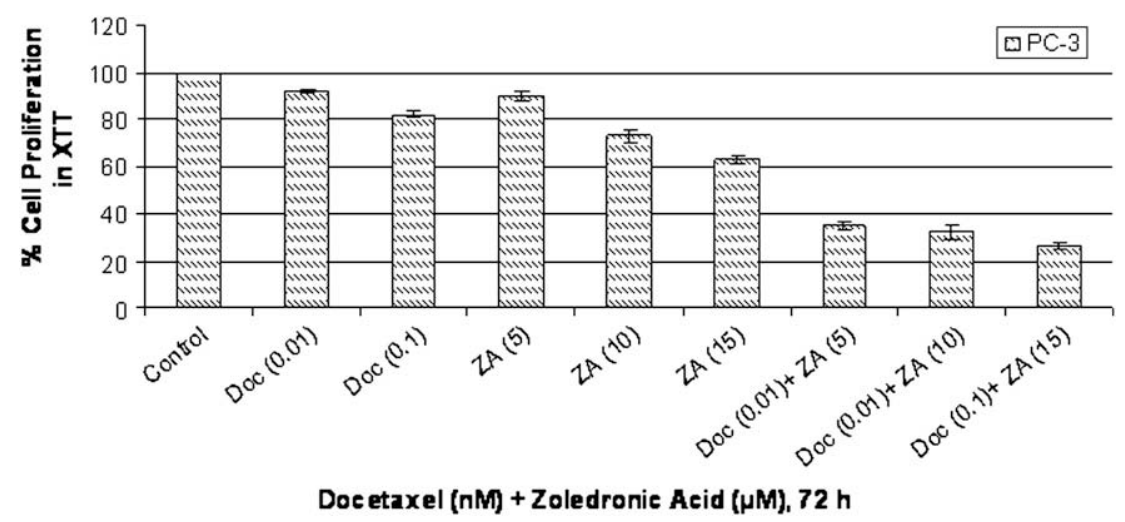

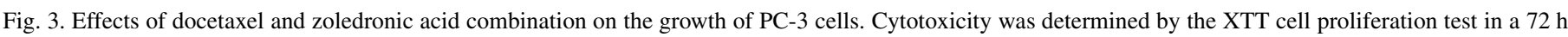

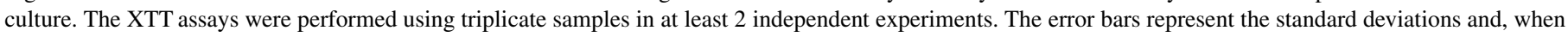

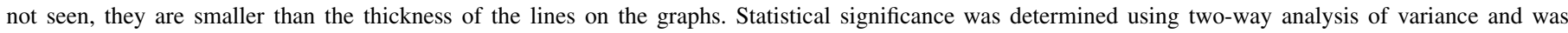
significant $(P<0.05)$. 


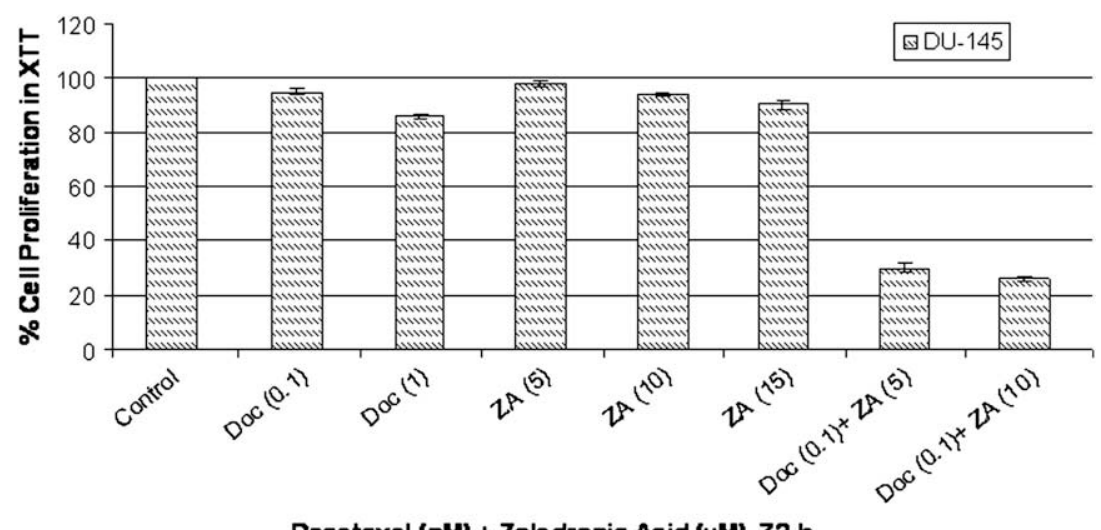

Docetaxel (nM) + Zole dronic Acid $(\mu M), 72 \mathrm{~h}$

Fig. 4. Effects of docetaxel and zoledronic acid combination on the growth of DU-145 cells. Cytotoxicity was determined by the XTT cell proliferation test in a $72 \mathrm{~h}$ culture. The XTT assays were performed using triplicate samples in at least 2 independent experiments. The error bars represent the standard deviations and, when not seen, they are smaller than the thickness of the lines on the graphs. Statistical significance was determined using two-way analysis of variance, and was significant $(P<0.05)$.

quantified the levels of mono-oligo nucleosome fragments by Cell Death Detection Kit (Roche Applied Science, Mannheim, Germany). The results of DNA fragmentation analyses clearly showed that combinations of both agents induced apoptosis to a greater extent than either agent alone.

There were 2.9- or 5.5-fold increase in DNA fragmentation in $0.1 \mathrm{nM}$ docetaxel or $15 \mu \mathrm{M}$ zoledronic acid exposed PC-3 cells, respectively, compared with untreated controls, while the combination of both resulted in a 7.7-fold increase in DNA fragmentation (Fig. 5). On the other hand, in $1 \mathrm{nM}$ docetaxel or $10 \mu \mathrm{M}$ zoledronic acid, or the combination of both on DU145 cells, there were 1.8- or 1.7- and 13.1-fold increase in DNA fragmentation, respectively, as compared to untreated controls (Fig. 6). The same set of experiments were conducted with the positive control of kit and have observed a significant increase in DNA fragmentation (data not shown). The data in Figs. 5 and 6 show that combination of both drugs induced apoptosis through DNA fragmentation significantly more as compared to any agent alone.

\subsection{Caspase 3/7 enzyme activity has been increased in response to combination of docetaxel and zoledronic acid more than any agent could induce by itself in human prostate cancer cells}

Caspases are commonly referred to as the hangmen of apoptosis. The activation of many forms of caspases happens in many cells undergoing apoptosis. To evaluate whether caspases play roles in docetaxel and zoledronic acid-induced apoptosis of PC-3 and DU-145 cells, we measured the levels of caspase 3/7 using Caspase-Glo 3/7 assay. One another important goal of the examining the changes in caspase $3 / 7$ enzyme activity was to determine the possible synergistic/additive effects of combination of docetaxel and zoledronic acid.

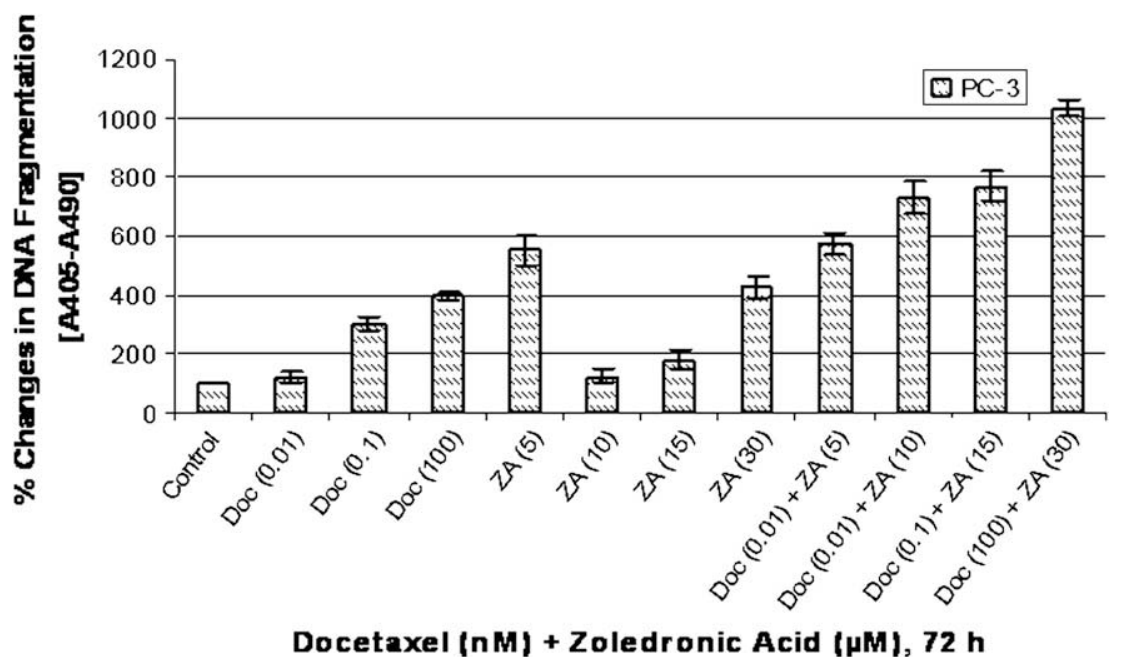

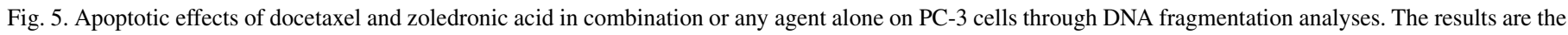

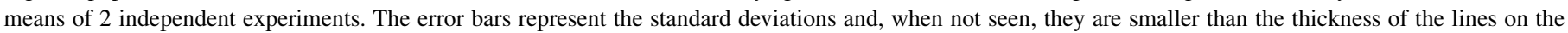
graphs. $P<0.05$ was considered significant. 


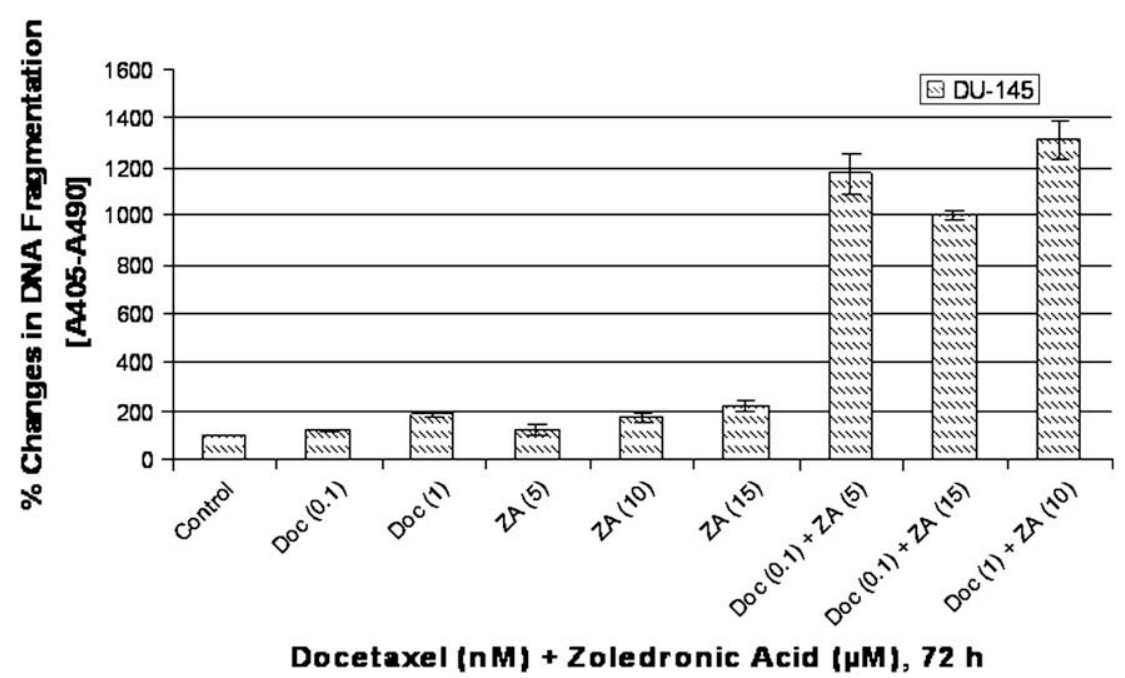

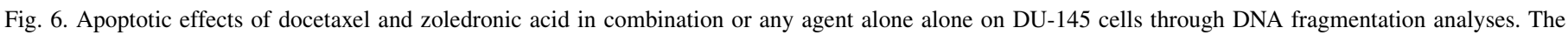

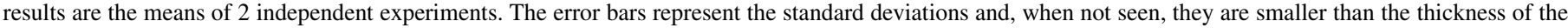
lines on the graphs. $P<0.05$ was considered significant.

The results revealed that there was a dose-dependent increase in caspase 3/7 enzyme activity in docetaxel or zoledronic acid in both PC-3 and DU-145 cells. Specifically, PC-3 cells exposed to $0.1 \mathrm{nM}$ docetaxel and $15 \mu \mathrm{M}$ zoledronic acid showed 1.73- or 2.14-fold increase in caspase 3/7 enzyme activity respectively, as compared to untreated controls, while their combination resulted in 4.1 times increase in caspase 3/7 enzyme activity (Fig. 7).

A similar set of experiments were conducted with DU-145 cells and the results showed that there were 1.9- and 3-fold increase in caspase 3/7 enzyme activity in $1 \mathrm{nM}$ docetaxel and $10 \mu \mathrm{M}$ zoledronic acid applied DU-145 cells, respectively, as compared to untreated controls. The combination of both resulted in 18.2 times increase in caspase $3 / 7$ enzyme activity compared to untreated controls (Fig. 8).

\subsection{Western-blot analyses showed that combination of docetaxel and zoledronic acid induces apoptosis through significantly downregulating antiapoptotic Bcl-2 gene in human prostate cancer cells}

Bcl-2 family proteins are overexpressed in many types of cancers. Although there are different types of proteins in this family, Bcl-2 protein was specifically recognized to be a therapeutic target in non-Hodgkin's lymphoma, chronic lymphocytic leukemia, prostate cancer, melanoma and some others. We have clearly shown that in PC-3 cells exposed to $100 \mathrm{nM}$ docetaxel and $30 \mu \mathrm{M}$ zoledronic acid, there were significant decreases in protein levels of Bcl-2 as compared to any agent alone applied cells (Fig. 9). The same results were also obtained with DU-145 cells (data not shown). These data

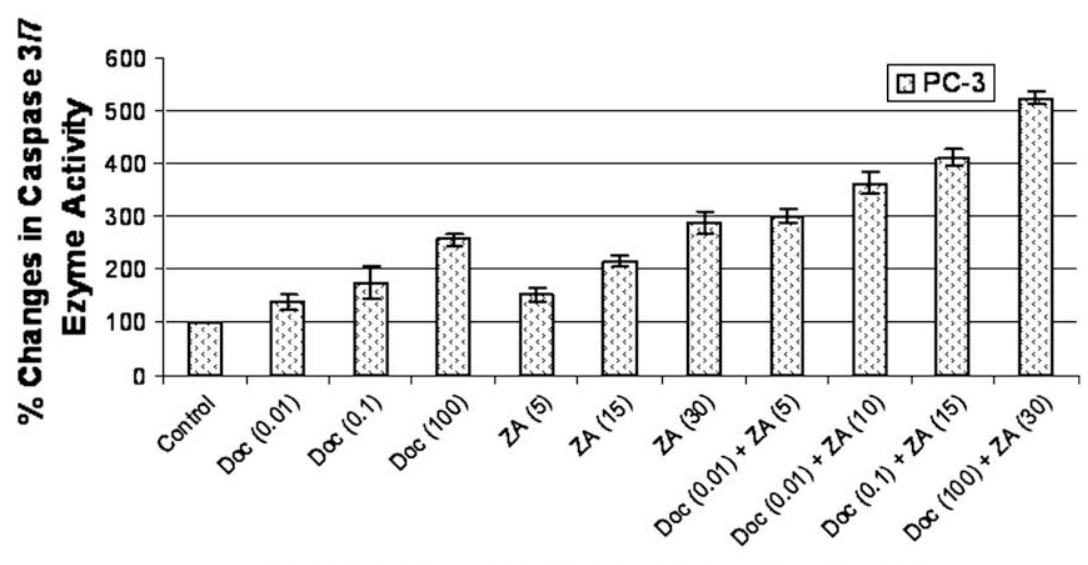

Doc etaxel (nM) + Zoledronic Acid ( $\mu \mathrm{M}), 72 \mathrm{~h}$

Fig. 7. Percent changes in caspase $3 / 7$ enzyme activity in docetaxel and zoledronic acid combination or any agent alone exposed PC-3 cells. The results are the means of 2 independent experiments. The error bars represent the standard deviations and, when not seen, they are smaller than the thickness of the lines on the graphs. $P<0.05$ was considered significant. 


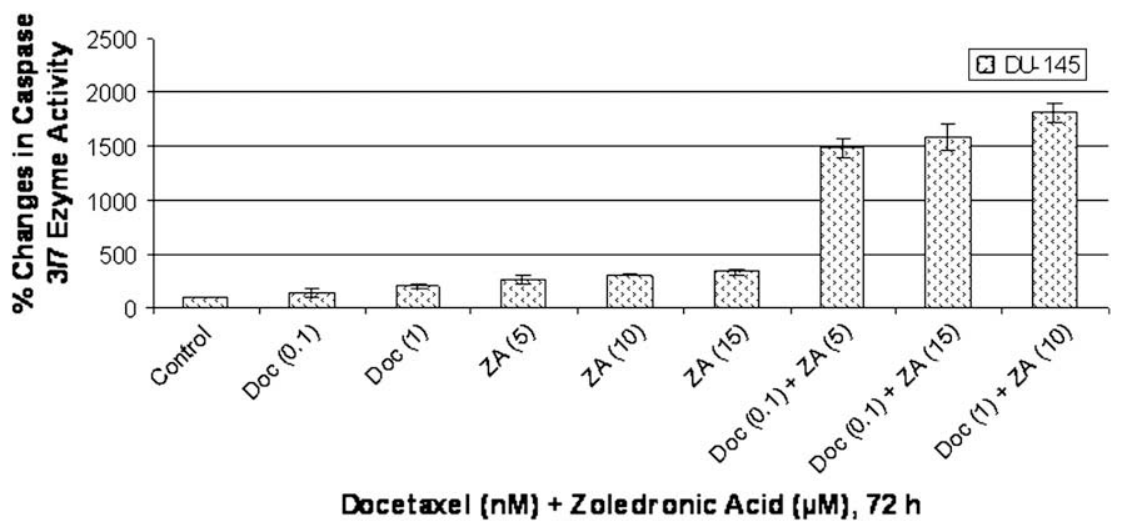

Fig. 8. Percent changes in caspase 3/7 enzyme activity in docetaxel and zoledronic acid combination or any agent alone exposed DU-145 cells. The results are the means of 2 independent experiments. The error bars represent the standard deviations and, when not seen, they are smaller than the thickness of the lines on the graphs. $P<0.05$ was considered significant.

indicated that docetaxel and zoledronic acid-induced prostate cancer cell apoptosis through downregulating protein levels of antiapoptotic Bcl-2 gene (Fig. 9).

\section{Discussion}

Docetaxel has been approved for the treatment of hormone and drug resistant prostate cancer patients and exhibits its cytotoxic effect due to decreased proliferation and induction of apoptosis (Berthold et al., 2008). Zoledronic acid is the most potent member of bisphosphonates that was shown to be standard therapy for patients with bone metastasized hormonerefractory prostate cancer and these agents decrease skeletal related events (Saad, 2002; Saad et al., 2004). Zoledronic acid was also shown to have anti-tumoral effects on prostate cancer cells through induction of apoptosis, inhibition of cell proliferation and angiogenesis (Oades et al., 2003).

Based on the literature, we have examined the possible synergistic cytotoxic and apoptotic effects of docetaxel and zoledronic acid combination in hormone-refractory PC-3 and DU-145 prostate cancer cells. We have clearly shown that docetaxel and zoledronic acid combination exerts a significant degree of cytotoxicity on PC-3 and DU-145 prostate carcinoma cells as compared to any agent alone. These cells are ideal models to study the effects and mechanisms of various anticancer agents since they represent the very high aggressive nature of metastatic human prostate cancers. Our results revealed that docetaxel and zoledronic acid was significantly cytotoxic in both PC-3 and DU-145 cells, in a dose- and time-dependent manner. Antiproliferative concentrations of combinations of these agents used in our study were in acceptable doses for in vivo administration. It was also shown by our studies that apoptosis was induced in prostate carcinoma cells with significant cytotoxicity, no matter which agent was applied first. Additionally, we demonstrated that there was a concentration dependent increase in caspase 3/7 enzyme activity in prostate carcinoma cells exposed to zoledronic acid or docetaxel and combinations of both.

In vitro treatment of different human cancer cells with docetaxel is associated with induction of apoptosis via phosphorylation and inactivation of the $\mathrm{Bcl}-2$ protein (Yoshino et al., 2006). Overexpression of $\mathrm{Bcl}-2$ has been implicated in the progression of prostate cancer to an androgen-independent stage (Huang et al., 2003; Lin et al., 2007; Rothermund et al., 2002). By different groups, it was also found that zoledronic acid inhibits cell proliferation and induces apoptosis through induction of DNA fragmentation and downregulation of Bcl-2 (Lee et al., 2001; Dumon et al., 2004; Caraglia et al., 2007). Based on the mentioned activities of docetaxel and zoledronic acid, we examined the possible augmented effects of their combination in PC-3 and DU-145 cells and searched for the changes in signalling pathways in response to any agent alone and combinations of both. It was clearly shown by our western studies that there was a significant decrease in protein levels of Bcl-2 in PC-3 and DU-145 cells exposed to combinations of both agents as compared to any agent alone or untreated controls. These results indicate that combinations of both agents induced apoptosis through downregulating antiapoptotic Bcl-2 protein.

Nowadays, treatment of androgen-independent prostate cancer still represents a challenge for clinicians. Thus, novel and effective approaches may provide an important avenue for the

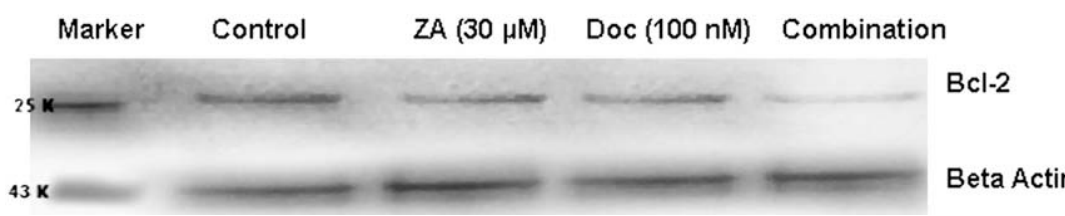

Fig. 9. Changes in protein levels of antiapoptotic Bcl-2 gene in PC-3 cells exposed to docetaxel or zoledronic acid and the combination of both as compared to untreated controls by western blotting. 
treatment of these groups of patients. In conclusion, we strongly suggest that docetaxel and zoledronic acid combination is a good candidate for this challenging era of daily oncologic practice. And also, from the clinical point of view, the combination of docetaxel and zoledronic acid might allow a reduction in docetaxel doses and, in this way, may diminish docetaxel adverse effects while maintaining the therapeutic effect in hormone-refractory prostate cancer patients.

\section{References}

Berthold DR, Pond GR, Soban F, De WR, Eisenberger M, Tannock IF. Docetaxel plus prednisone or mitoxantrone plus prednisone for advanced prostate cancer: updated survival in the TAX 327 study. J Clin Oncol 2008; 26:242-5.

Caraglia M, Marra M, Leonetti C, Meo G, D'alessandro AM, Baldi A, et al. R115777 (Zarnestra)/Zoledronic acid (Zometa) cooperation on inhibition of prostate cancer proliferation is paralleled by Erk/Akt inactivation and reduced Bcl-2 and bad phosphorylation. J Cell Physiol 2007;211:533-43.

Chou TC, Talalay P. Quantitative analysis of dose-effect relationships: the combined effects of multiple drugs or enzyme inhibitors. Adv Enzyme Regul 1984;22:27-55.

Corey E, Brown LG, Quinn JE, Poot M, Roudier MP, Higano CS, et al. Zoledronic acid exhibits inhibitory effects on osteoblastic and osteolytic metastases of prostate cancer. Clin Cancer Res 2003;9:295-306.

Dumon JC, Journe F, Kheddoumi N, Lagneaux L, Body JJ. Cytostatic and apoptotic effects of bisphosphonates on prostate cancer cells. Eur Urol 2004; 45:521-8.

Gligorov J, Lotz JP. Preclinical pharmacology of the taxanes: implications of the differences. Oncologist 2004;2(Suppl. 9):3-8.

Haldar S, Basu A, Croce CM. Bcl2 is the guardian of microtubule integrity. Cancer Res 1997;57:229-33.
Hanauske AR, Degen D, Hilsenbeck SG, B1ssery MC, Von Hoff DD. Effects of Taxotere and taxol on in vitro colony formation of freshly explanted human tumor cells. Anticancer Drugs 1992;3:121-4.

Huang JM, Lin TY, Chang D, Lin SL, Ying SY. Truncated Bcl-2, a potential pre-metastatic marker in prostate cancer. Biochem Biophys Res Commun 2003;306:912-7.

Lee MV, Fong EM, Singer FR, Guenette RS. Bisphosphonate treatment inhibits the growth of prostate cancer cells. Cancer Res 2001;61: 2602-8.

Lin Y, Fukuchi J, Hiipakka RA, Kokontis JM, Xiang J. Up-regulation of Bcl-2 is required for the progression of prostate cancer cells from an androgendependent to an androgen-independent growth stage. Cell Res 2007;17: 531-6.

Oades GM, Senaratne SG, Clarke IA, Kirby RS, Colston KW. Nitrogen containing bisphosphonates induce apoptosis and inhibit the mevalonate pathway, impairing Ras membrane localization in prostate cancer cells. $\mathrm{J}$ Urol 2003;170:246-52.

Rothermund CA, Kondrikov D, Lin MF, Vishwanatha JK. Regulation of Bcl-2 during androgen-unresponsive progression of prostate cancer. Prostate Cancer Prostatic Dis 2002;5:236-45.

Saad F. Zoledronic acid significantly reduces pathologic fractures in patients with advanced-stage prostate cancer metastatic to bone. Clin Prostate Cancer 2002;1:145-52.

Saad F, Gleason DM, Murray R, Tchekmedyian S, Venner P, Lacombe L, et al. Long-term efficacy of zoledronic acid for the prevention of skeletal complications in patients with metastatic hormone-refractory prostate cancer. J Natl Cancer Inst 2004;96:879-82.

Yoshino T, Shiina H, Urakami S, Kikuno N, Yoneda T, Shigeno K, et al. Bcl-2 expression as a predictive marker of hormone-refractory prostate cancer treated with taxane-based chemotherapy. Clin Cancer Res 2006;12: 6116-24.

Zhao ZG, Ma QZ, Xu CX. Abrogation of heat-shock protein (HSP)70 expression induced cell growth inhibition and apoptosis in human androgen-independent prostate cancer cell line PC-3m. Asian J Androl 2004;6:319-24. 